\title{
CARACTERIZACION ECOLOGICA DE HUMEDALES DE LA ZONA SEMIARIDA EN CHILE CENTRAL
}

\section{WETLANDS ECOLOGICAL CHARACTERIZATION OF CENTRAL CHILE SEMI-DRY AREA}

\author{
Ricardo Figueroa ${ }^{1}$, María Luisa Suarez², Asunción Andreu ${ }^{3}$ \& Víctor H. Ruiz \& \\ María R. Vidal -Abarca \\ ${ }^{1}$ Unidad de Sistemas Acuáticos, Centro EULA-Chile, Universidad de Concepción. Casilla 160 C, Concepción, Chile. \\ Email: rfiguero@udec.cl
${ }^{2}$ Departamento de Ecología e Hidrología, Universidad de Murcia, España. \\ ${ }^{3}$ Departamento de Zoología y Antropología Física, Universidad de Murcia, España. \\ ${ }^{4}$ Departamento de Zoología, Facultad de Ciencias Naturales y Oceanográficas, Universidad de Concepción.
}

\begin{abstract}
RESUMEN
Uno de los ecosistemas naturales más amenazados del planeta son los humedales, que a pesar de su reconocida importancia, son poco valorados, lo que cobra mayor relevancia en Chile donde existen muy poca información sobre este tipo de ambientes. Este trabajo reúne antecedentes sobre tipología, hidrología, usos del suelo, unidades paisajísticas e impactos de 20 humedales de las regiones IV y V (Coquimbo y Valparaíso, Chile Central). El período de muestreo abarcó del 2 al 10 de julio de 2007 correspondiente a la fase húmeda del ciclo hidrológico anual. Se analizaron distintos parámetros físico-químicos: profundidad, ancho de lámina de agua, tipología del sustrato, temperatura del agua, $\mathrm{pH}$ y conductividad; y biológicos: vegetación acuática y de ribera, macroinvertebrados y fauna piscícola. Finalmente, para determinar el estado de conservación de estos humedales se aplicó el Índice del Estado de Conservación de Ecosistemas Lénticos Someros (ECELS), propuesto por la Agencia Catalana del Agua. En general se trata de ecosistemas de tamaño medio, no superior a 50 has, aunque el Complejo del Yali (región V) supera las 500 ha. La mayoría son permanentes, con valor medio de $\mathrm{pH}$ de 7.84 (rango = 7.1 y 9.4) y conductividad de 11918,16 $\mu \mathrm{S} / \mathrm{cm}$, pero con un rango muy amplio (entre 665 y $52200 \mu \mathrm{S} / \mathrm{cm}$ ), lo cual muestra el distinto origen de las aguas que mantienen estos humedales. En cuanto a la vegetación acuática Ceratophyllum chilensis, es el macrófito más habitual, pero siempre en humedales de baja conductividad. La comunidad de invertebrados acuáticos está compuesta por 42 taxa pertenecientes a 29 familias. Los insectos es el grupo más diversificado (17 familias) y de ellos, los dípteros con 8 familias. En cuanto a la fauna piscícola, se recolectaron cuatro especies: la lisa (Mugil cephalus) de origen marino, y tres exóticas: gambusia (Gambusia holbrooki), gambusia manchada (Cnesterodon decemmaculatus), y chanchito (Cichlasoma facetum). La aplicación del ECELS evaluó sólo dos humedales de máxima calidad, 5 la calidad fue buena, en 7 fue media y en 6 mala (5) o muy mala (1).
\end{abstract}

Palabras Claves: Chile Central, ECELS, Humedales, macroinvertebrados, peces.

\section{ABSTRACT}

Wetlands are one of the most threatened natural ecosystems on the planet. In spite of their recognized importance, wetlands are not highly valued. This is particularly true in Chile, where little information is available regarding this type of environment. This paper presents data on the typology, hydrology, land uses, landscape units, and impact of 20 wetlands in regions IV (Coquimbo) and V (Valparaíso) of central Chile. Samples were taken from 2 to 10 July 2007, during the wet phase of the annual hydrological cycle. We analyzed a variety of physical-chemical (depth, width of the water surface, substrate typology, temperature, $\mathrm{pH}$, water conductivity) and biological parameters (aquatic and shoreline vegetation, macroinvertebrates, ichthyic fauna). We used the Index of the State of Conservation of Shallow Lentic Ecosystems (ECELS), proposed by the Catalan Water Agency, to determine the state of conservation of these wetlands. In general, this index deals with mid-sized ecosystems that do not exceed 50 ha although, herein, the Yali complex $($ Region V) is an exception (>500 ha). Most of these systems are permanent and average 7,84 in $\mathrm{pH}(\mathrm{range}=7,1-9,4)$ and $11918,2 \mu \mathrm{S} / \mathrm{cm}$ in conductivity (range $=665-52200 \mu \mathrm{S} / \mathrm{cm}$ ). The very wide range showed different origins of the waters that sustain these wetlands. As for the aquatic vegetation, Ceratophyllum chilensis is the most common macrophyte 
Humedales de la zona semiárida chilena: FiguEROA, R. ET AL.

in low-conductivity wetlands. The aquatic invertebrate community is composed of 42 taxa belonging to 29 families. Insects constitute the most diverse group (17 families), particularly the dipterans ( 8 families). Four fish species were collected during sampling. One, flathead mullet or lisa (Mugil cephalus), has marine origins and the other three are exotic species: mosquitofish or gambusia (Gambusia holbrooki), ten spotted live-bearer (Cnesterodon decemmaculatus), and chameleon cichlid (Cichlasoma facetum). According to the ECELS, the quality of these wetlands is maximum in only two cases, good in five, regular in seven, poor in another five cases, and very poor in one case.

Key word: Central Chile, ECELS, wetlands, macroinvertebrates, fishes.

\section{INTRODUCCION}

Uno de los ecosistemas naturales más amenazados del planeta son los humedales, tanto por la acción humana asociada al crecimiento urbano que los estrangula transformándolos en canales o pozas temporales receptoras de basura (Boavida 1999; Mitsch 1994), como por el cambio climático que afecta a su tamaño, estructura, hidrología y comunidades biológicas (Moreno 2005; Finlayson 1999). Además, son ecosistemas muy difíciles de abordar debido a su diversidad y complejidad, al desarrollarse en gradientes hidrológicos desde hábitats terrestres hasta los estrictamente acuáticos (WFD CIS Guidance Doc $\mathrm{n}^{\mathbf{o}}$ 12, 2003).

Especial interés tienen aquellos situados en regiones semiáridas, entre otras razones, porque en ellas se localizan la mayor diversidad de tipos de humedales, desde criptohumedales a humedales con lámina de agua libre permanente, pasando por sistemas temporales (CAM 2003; Vidal-Abarca et al. 2000). Sin embargo, estos sistemas son poco valorados y su importancia no está acorde con la baja cantidad de estudios que se generan en estas regiones. En esta situación se encuentran los humedales de Chile, particularmente los situados en la región mediterránea norte, que es una de las más amenazadas por la densidad de población que concentra (Figueroa et al. 2007) y que comienzan a ser comprimidos por el desarrollo urbano. Chile posee una extensión media de $4200 \mathrm{~km}$ de longitud y un ancho promedio de $200 \mathrm{~km}$, con una diversidad de climas y procesos de escurrimientos superficiales diferenciales, donde el agua que cae en la cordillera de los Andes, especialmente en la zona centro sur, se evacua rápidamente en ríos de buen torrente y en su mayoría, permanentes y de llegada al mar. No obstante, de este a oeste, existen planicies, depresiones y formaciones geológicas relevantes en la estructuración del paisaje (e.g. fallas tectónicas, glaciaciones, dunas costeras) que permiten la acumulación de agua y la formación de importante sistemas lacustres que han recibido atención en variadas publicaciones (e.g. Parra et al. 2003; Mardones 1999; Mardones \& Reuther 1999). Esta situación se presenta con menos fuerza en la zona norte del país, y es de excepcional interés en la zona semiárida, donde la formación de lagunas costeras sobre terrazas marinas y con eventual conexión al mar, dan origen a un sistema complejo de humedales, que fuera de su reconocida importancia como refugio de aves, no han sido estudiados en sus características ecológicas. Actualmente existe un reciente interés por estudiar y proteger a los humedales en Chile (CONAMA 2005; Luna 2005), aunque la realidad es que la mayor parte de ellos carece de status de protección ambiental y programas de manejo que ayuden a equilibrar explotación/conservación. Esta situación, en general, se ve agudizada por la falta de información sobre su dinámica hidrológica, biológica y ecológica. No obstante, algunos sistemas lacustres chilenos han sido reconocidos a nivel internacional. De hecho, Chile cuenta con 9 sitios Ramsar, dos de los cuales localizados entre regiones IV y V del país (La laguna de Conchalí y el humedal El Yali), son parte de este estudio. La laguna de Conchalí, tiene categoría de Santuario de la Naturaleza, con una superficie de 50.9 hectáreas. Es de propiedad de la Sociedad Minera Los Pelambres, empresa que solicitó su protección. Se ubica en el borde costero del sector denominado «Punta Chungo», en la Comuna Los Vilos y corresponde a un humedal costero rodeado por un cordón de dunas (CONAMA 2002). Alberga flora y fauna terrestre y acuática de interés, con alta diversidad de especies, además de corresponder a un punto importante en la ruta de migración de aves a lo largo de la costa chilena. Constituye también un hábitat importante para peces con problemas de conservación; y posee una flora acuática bien desarrollada que permite la alimentación, refugio y desove de gran número de especies de peces y pequeños crustáceos, parte de la cadena alimentaria de las aves que allí residen (Rojas \& Tabilo-Valdivieso 2004). El humedal del Yali, ha sido objeto de estudios hidrológicos y biológicos (CONAMA 2004), dado su condición de protección como 
Humedal RAMSAR. En realidad se trata de un complejo de humedales localizados en la Comuna de Santo Domingo (V región). Alberga más de 115 especies de aves que, representan el $25 \%$ del total de especies que hay en Chile (Victoriano et al. 2006). Además, este humedal brinda refugio a unas 18 especies de aves migratorias del Amazonas, Ecuador, Estados Unidos y Canadá.

Otros humedales de la región IV (Coquimbo), han sido objeto de estudio por parte de CONAMA, dentro de la Estrategia Nacional y Plan de Acción de la Biodiversidad (CONAMA 2002). En este documento se recoge información y catalogan los humedales de la región de Coquimbo, siempre desde un punto de vista descriptivo. Entre los estudios hidrológicos de la región IV, destaca el de Squeo et al. (2006) sobre la dinámica de las aguas subterráneas en el humedal de El Romeral. Luna (2005) realiza una revisión detallada sobre los humedales de la IV región. Menos información general existe, para los humedales de la V Región, aunque en un documento de CONAMA (2004), se trata el humedal del Yali. En relación con las comunidades de organismos acuáticos, no existen estudios específicos sobre la vegetación acuática e invertebrados acuáticos de estos ambientes. Solo recientemente ha sido publicado un número especial de la revista Gayana (Volumen $70 \mathrm{~N}^{\circ} 1,2006$ ), que recoge buena parte de la diversidad de organismos dulceacuícolas de Chile, incluyendo revisiones de distintos grupos de organismos acuáticos continentales, no obstante, no hacen mención a taxa propias de los sistemas de humedales.

Los peces han recibido mayor atención, Vila et al. (1999) Campos et al. (1998) y, estudian los peces límnicos de Chile y analizan el estado de conservación de los peces nativos. Dyer (2000), revisa su sistemática y biogeografía. Ruiz \& Marchant (2004), publica un completo catalogo de peces de aguas continentales y estuarinos. También son tratados por Vila et al. (2006) en macrófitas y peces de los sistemas límnicos de Chile. En cuanto a los invertebrados acuáticos, Crespo \& Baessolo (2002), en un estudio sobre biogeografía y taxonomía del género Artemia, recogen información de este género en varios humedales de las regiones IV y V, al igual que el estudio comparativo de Castro et al. (2006) entre México y Chile. Los anfípodos del género Hyalella han sido estudiados por González (2003). Estudios generales sobre humedales estuarinos han sido realizados, por Stuardo et al. (1993) y Valdovinos et al. (1993). Frente a la falta sistemática de información que permita abordar estudio de protección, el presente trabajo reúne información sobre tipología, hidrología, unidades paisajísticas e impactos, realizando por primera vez un intento de clasificación de estos ecosistemas de acuerdo a características geomorfológicas, físicoquímicas y biológicas.

\section{MATERIALES Y METODOS}

\section{Area De Estudio}

En Chile se pueden distinguir tres regiones climáticas: Desértica en el norte, Mediterránea y Templada en su zona central y Húmeda-fría en la región sur. El clima mediterráneo chileno se localiza la entre los $27^{\circ}$ y $\operatorname{los} 38^{\circ} \mathrm{S}$, se caracteriza por ser templado a causa de la influencia marítima, con cuatro estaciones muy marcadas, inviernos fríos y húmedos y veranos cálidos y secos. En su límite norte, la región IV presenta una precipitación media anual de $222 \mathrm{~mm}$ año-1 $^{-1}$, con una superficie de $40.656 \mathrm{~km}^{2}$ y sus principales recursos hídricos provienen de los Ríos Elqui, Choapa y Limarí, con una disponibilidad de agua de $1411 \mathrm{~m}^{3} /$ habitantes. En la región V, de Valparaíso, los valores de precipitación llegan a 434 mm/año, con una superficie de $16341 \mathrm{~km}^{2}$ y una disponibilidad de agua de $995 \mathrm{~m}^{3}$ /habitante.

En estas regiones se seleccionaron un total de 20 humedales, a través de un gradiente latitudinal costero. El período de muestreo abarcó del 2 al 10 de Julio de 2007, correspondiente a la fase húmeda (otoño-invierno) del ciclo hidrológico anual, no obstante, las condiciones excepcionales de escasa lluvia del año, facilitaron el acceso a varios de estos sistemas que suelen encontrarse saturados de agua. La Figura 1 muestra la localización de las estaciones de muestreo; las características geográficas y tipología de los 20 humedales estudiados son presentadas en la tabla I. Para todos ellos se recogió información geográfica, sobre su tipología, hidrología, usos del suelo, unidades paisajísticas e impactos. La georeferenciación fue realizada mediante el uso de un receptor GPS que está especialmente indicado para trabajar con sistemas de información geográfica (SIG), ya que permite exportar cartografía e importarla para su actualización. De cada localidad muestreada se ha obtenido una serie de imágenes digitales que reflejan el aspecto general de la misma y aquellos detalles adicionales que se han considerado 
de interés, tanto relativos a su descripción, como a los usos, actividades e impactos detectados durante su reconocimiento.

PARÁMETros Físico-Químicos In Situ

En todos los humedales muestreados, se recogió información de distintos parámetros físicos y químicos como: profundidad y ancho de la lámina de agua, tipología del sustrato, temperatura del aire y del agua, $\mathrm{pH}$ con un $\mathrm{pH}$-metro Schott Mod. Handylab CG-836/2046 y la conductividad eléctrica mediante un conductivímetro Cole Parmer Mod. 19820.

\section{PARÁmetros Biológicos}

En cada uno de los humedales se registró la vegetación acuática y de ribera, se recogieron muestras de macroinvertebrados acuáticos, con una manga de 250 $\mu \mathrm{m}$ de luz de malla. El tipo de muestreo fue multihábitat (Jáimez-Cuéllar et al 2004 \& Zamora-Muñoz \& AlbaTercedor 1996), con lo que se aseguraba la recogida de la mayor diversidad posible de organismos. Las muestras se procesaron en terreno, para lo cual se vertía toda la captura en una bandeja blanca de donde se extraían los ejemplares diferentes. El muestreo cesaba cuando no se detectaba ningún espécimen nuevo. Los ejemplares recolectados fueron fijados en alcohol al $70 \%$ e individualizados para su posterior determinación en el laboratorio. La identificación se realizó bajo una lupa estereoscópica siguiendo literatura especializada (Domínguez et al. 2006; Fernández \& Domínguez 2002; Illies 1963).
Igualmente se muestreó la fauna piscícola, mediante una aproximación cualitativa. En cada localidad el método y protocolo para la captura era determinado in situ dependiendo del análisis detallado de las características del cuerpo de agua (Bain \& Stevenson 1999), donde previo a la pesca, se tomaban datos del hábitat y de las amenazas potenciales y/o reales de la zona. Los métodos empleados fueron activos, factibles en aguas someras y de alta conductividad que caracterizan a los cuerpos de agua estudiados, siendo: chinguillos (Mangos: 1,5-2 m, Sacadera: 40x40 cm, luz de malla: $1 \mathrm{~mm}$ ) y red de arrastre manual (Paño de 10 x 1,5 m; luz de malla -'3d $5 \mathrm{~mm}$ ). El primero es apropiado para ambientes someros con abundante vegetación acuática y poca corriente, el segundo es efectivo en ambientes someros con ( $<1 \mathrm{~m}$ de profundidad), escasa vegetación acuática, poca corriente y sustratos arenosos. Durante la realización de los muestreos se aplicó un criterio de carácter genérico para el desarrollo de los mismos: muestrear todos los hábitats someros del cuerpo de agua objeto de estudio (orillas libres, escasa vegetación, abundante vegetación, etc.) con la finalidad de detectar especies con requerimientos específicos. Así, pues los muestreos fueron llevados a cabo exclusivamente en las áreas someras de los humedales prospectados. No obstante, en muchas localidades la efectividad de la red de arrastre manual resultó baja debido a la cantidad de fangos blandos arrastrados por la misma, por lo que fue desestimado su uso en humedales con características similares.
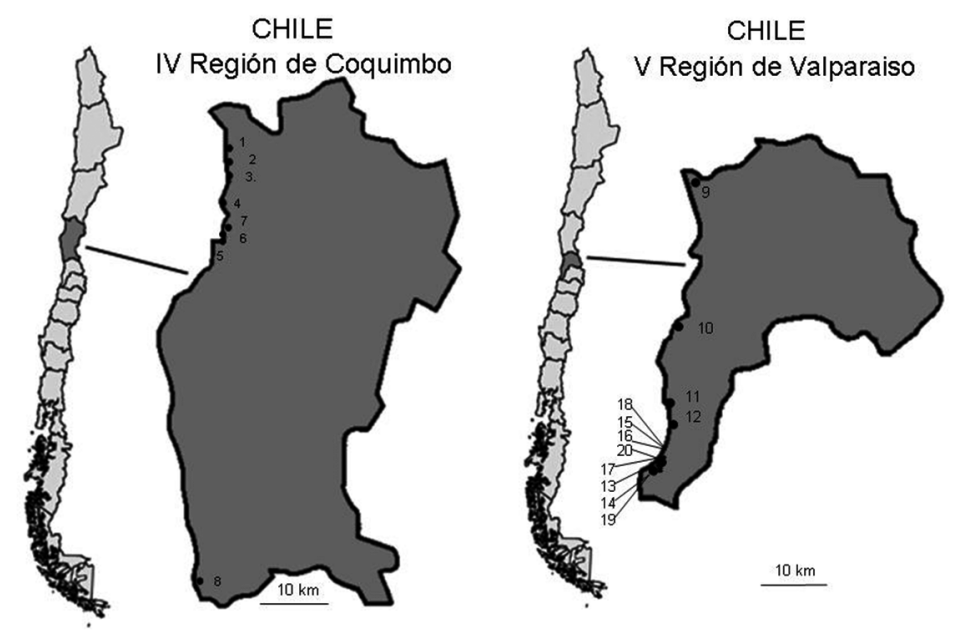

FIGURA 1. Localización geográfica de los humedales prospectados en Chile. La numeración se corresponde con la Tabla I.

FIGURE 1. Location of wetlands prospective in Chile (The numbering corresponds to Table I). 
Gayana 73(1), 2009

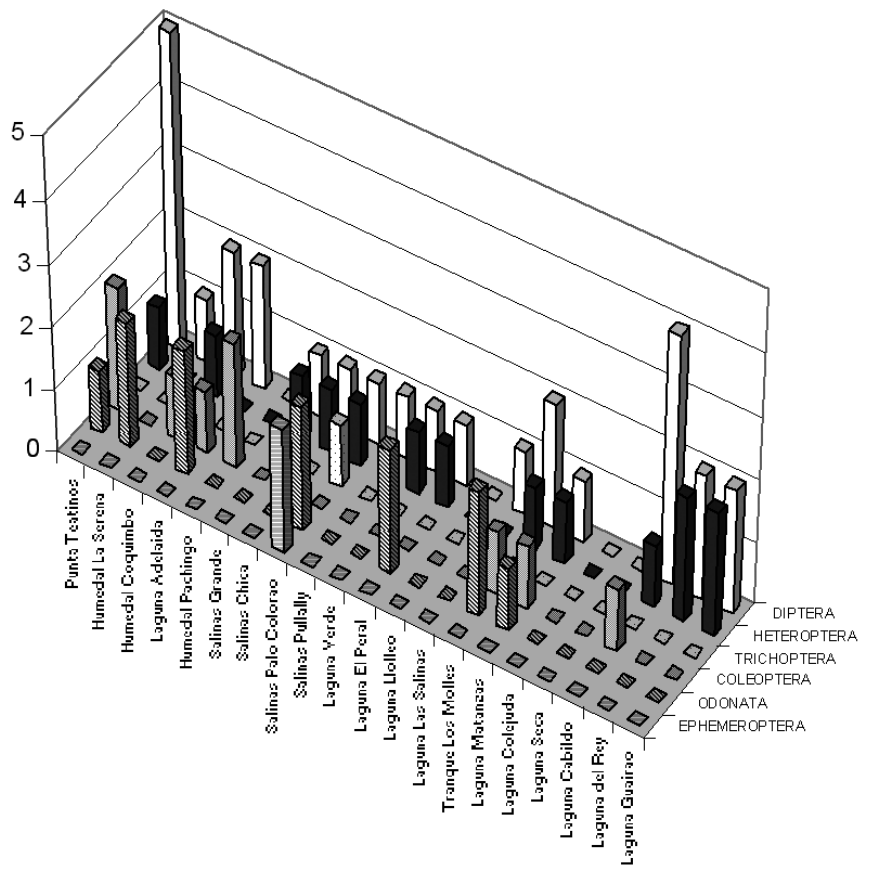

FiguRa 2. Distribución del número de familias de insectos acuáticos en los humedales estudiados.

FIGURE 2. Distribution of families of aquatic insects in the wetlands studied.

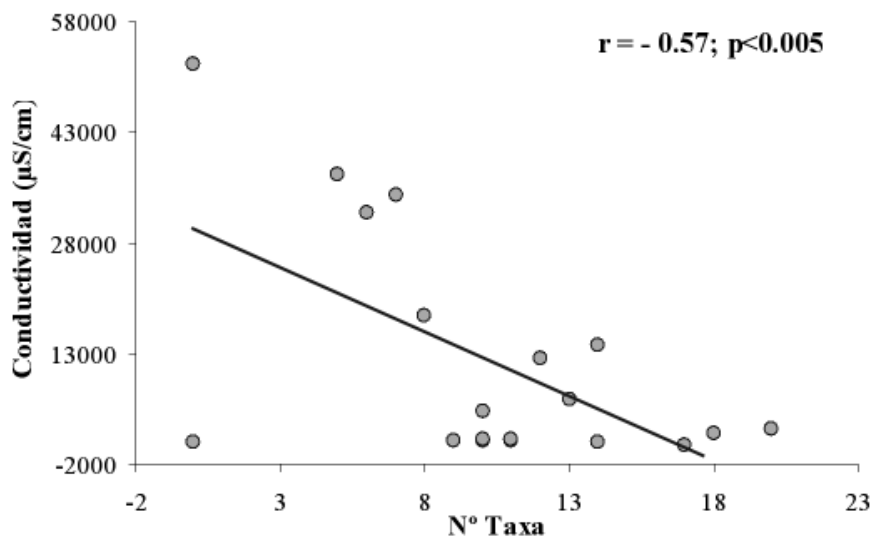

FIGURA 3. Relación entre el número de taxones de invertebrados acuáticos recolectados en los humedales estudiados y la conductividad $(\mu \mathrm{S} / \mathrm{cm})$.

FIGURE 3. Relationship between number of collected aquatic invertebrates and the conductivity $(\mu \mathrm{S} / \mathrm{cm})$ in the wetlands studied. 
Indice Del Estado De Conservación De Ecosistemas LÉNTICOS SOMERos (ECELS)

Para determinar el estado de conservación de los humedales se aplicó el Índice del Estado de Conservación de Ecosistemas Leníticos Someros (ECELS), propuesto por la Agencia Catalana del Agua (2004). Este índice valora en 5 bloques, aspectos relativos a la morfología del humedal; construcciones, infraestructuras y usos humanos; aspecto del agua; vegetación de helófitos y vegetación sumergida y flotante. El Bloque 1, valora la pendiente de la franja litoral y es modulada (corregida) por la presencia de construcciones o aterramientos que alteran dicha franja. El mayor valor para este bloque se obtiene cuando la pendiente es < del $25 \%$. El Bloque 2 valora las alteraciones provocadas por construcciones, infraestructuras como carreteras, extracciones de agua o usos humanos del territorio que afectan significativamente al humedal. El Bloque 3 se refiere al aspecto del agua, de forma cualitativa, valorándose el olor y el color. El Bloque 4 analiza la vegetación de helófitos de la franja litoral, puntuando de forma positiva la ocupación de la comunidad vegetal de toda la franja y la diversidad de especies. Por el contrario, se penaliza, la dominancia de alguna planta sobre las demás. Se valora también la temporalidad del agua. Finalmente, el Bloque 5 analiza la vegetación sumergida y flotante, la cantidad y cobertura de cada una de ellas en el humedal. Se modula y corrige por la dominancia de alguna de las formaciones.

El valor final, se obtiene de la suma de los bloques y se valora su calidad en 5 clases, que pueden ser ilustradas por un color: Calidad Muy Buena: azul (entre 80-100), Calidad Buena: verde (entre 60-80), Calidad Media: amarillo (entre 4060), Calidad Mala: naranja (entre 20-40) y Calidad Muy Mala: rojo (entre 0-20).

\section{RESULTADOS}

\section{PARÁMETROS FísICO-QUímICOS}

Los datos relativos a los parámetros físicos, químicos y origen del agua de los humedales estudiados son presentados en la Tabla I. En general, se trata de ecosistemas de tamaño medio, no superior a 50 ha, aunque el Complejo del Yali supera las 500 ha en su conjunto. La mayoría presentan aguas permanentes, excepto la Laguna Seca del complejo Yali que tiene carácter temporal. En cuanto al origen del agua, suele existir una combinación entre agua subterránea y de escorrentía superficial. Los que están más cerca del mar, presentan una dinámica hidrológica relacionada con el medio marino.

La contribución de cada fracción al balance hidrológico final es diferente y depende de factores geográficos y topográficos, lo cual se aprecia bien en los valores de conductividad que presentan un valor medio de $11918,2 \mu \mathrm{S} / \mathrm{cm}$, pero con un rango de variación muy amplio (entre $665 \mu \mathrm{S} / \mathrm{cm}$ en Salinas Palo Colorao y $52200 \mu \mathrm{S} / \mathrm{cm}$ en la Laguna Colejuda), mostrando el distinto origen y movilidad de las aguas que mantienen los humedales. La temperatura del agua, durante el periodo de muestreo fue de $13,0^{\circ} \mathrm{C}$, con un rango entre $10,3^{\circ} \mathrm{C}$ medido en la Laguna Verde y $18.2^{\circ} \mathrm{C}$ en Salinas Grande. En cuanto al pH, el valor medio fue de 7.8, con un rango entre 7.1 y 9.4 en La Laguna del Rey y Salinas Palo Colorao, respectivamente.

PARÁmetros BiolóGicos

Como forma de establecer una primera aproximación a la estructura y complejidad de los humedales estudiados, se valoró las distintas unidades de vegetación palustre (Tabla II). Las formaciones más habituales son las de salinas (Sarcocornia fruticosa (L.) Scott., Spartina densiflora (Brongn) y distintas especies de Limnobium, juncales (Scirpus californicus (C.A. Mey.) Steud.), carrizales (Phragmites australis (Cav.) Trin. ex Steud.) y las mixtas como el juncalsaladar. También se han detectado las formaciones de Typha (Typha angustifolia, L.) y del arbusto nativo molle (Schinus latifolius,(Gill. ex Lindl.) Engler.) perteneciente a la familia Anacardiaceas, que puede alcanzar unos $10 \mathrm{~m}$ de altura y se localiza, preferentemente, en la región central de Chile. La Laguna Adelaida es la que presenta mayor diversidad de formaciones vegetales.

En relación con la vegetación acuática, en la Tabla II se presentan las especies más habituales encontradas. Ceratophyllum chilensis (Leyb.), es el macrófito más habitual, pero siempre se presenta en humedales de baja conductividad. Lemna gibba (L.), se encontró en un solo humedal (Laguna Verde), al igual que Ranunculus sp. (Laguna Guairao) y una apiacea en el Estero el Culebrón. Hay que destacar las densas formaciones de la cianofícea Anabaena sp. encontradas en los humedales del Complejo del Yali (Lagunas Matanzas y Cabildo), que dan aspecto denso e intenso color verde del agua. 
$\infty$ TABLA I. Localización, parámetros físico-químicos, origen del agua, impactos, estatus de protección y tipo de propiedad de los humedales prospectados en las regiones IV (Coquimbo) y V (Valparaíso) de Chile durante julio de 2007.

TABLE I. Location, physical and chemical parameters, water source, impact, protection status and property type of prospective wetlands in regions IV (Coquimbo) and V (Valparaiso), Chile, during July 2007.

\begin{tabular}{|c|c|c|c|c|c|c|c|c|c|c|c|c|c|c|c|}
\hline Código & Nombre & Localidad & Región & Fecha & Este & Norte & Tipología & $\begin{array}{c}\text { Superf. } \\
\text { (ha) }\end{array}$ & $\begin{array}{c}\mathrm{T}^{\mathrm{a}} \text { agua } \\
\left({ }^{\circ} \mathrm{C}\right)\end{array}$ & $\mathrm{pH}$ & $\begin{array}{l}\text { Conductiv. } \\
(\mu \mathrm{S} / \mathrm{cm})\end{array}$ & origen agua & Impactos & Protección & Propiedad \\
\hline $\mathrm{H} 1$ & $\begin{array}{l}\text { Punta Teatinos/ } \\
\text { Saladita }\end{array}$ & La Serena & IV & 04/07/2007 & 278771 & 6698703 & $\begin{array}{l}\text { Laguna litoral } \\
\text { permanente }\end{array}$ & 18 & 12,4 & 8,4 & 2800 & $\begin{array}{c}95 \% \\
\text { subterránea }\end{array}$ & $\begin{array}{l}\text { Basuras, presión } \\
\text { antrópica: } \\
\text { urbanización }\end{array}$ & no & Privada \\
\hline $\mathrm{H} 2$ & Humedal La Serena & La Serena & IV & 04/07/2007 & 280861 & 6690940 & $\begin{array}{l}\text { Desembocadura río } \\
\text { permanente }\end{array}$ & 14 & 14,5 & 7,3 & 1228 & río/mar & $\begin{array}{l}\text { Agricultura, } \\
\text { ganadería, } \\
\text { presión antrópica }\end{array}$ & no & $\begin{array}{c}\text { Privada y } \\
\text { publica }\end{array}$ \\
\hline $\mathrm{H} 3$ & $\begin{array}{l}\text { Humedal Coquimbo/ } \\
\text { Estero Culebrón }\end{array}$ & Coquimbo & IV & $04 / 07 / 2007$ & 275990 & 6683275 & $\begin{array}{l}\text { Humedal litoral } \\
\text { permanente }\end{array}$ & 18 & 13,9 & 8,01 & 950 & río/mar & $\begin{array}{l}\text { Basuras, } \\
\text { aterramiento, } \\
\text { vertedero }\end{array}$ & no & Privada \\
\hline $\mathrm{H} 4$ & $\begin{array}{l}\text { Laguna Adelaida/ } \\
\text { Lagunillas }\end{array}$ & La Serena & IV & 05/07/2007 & 272172 & 6665626 & $\begin{array}{l}\text { Humedal litoral } \\
\text { permanente }\end{array}$ & 21 & 14,6 & 8,6 & 14200 & estero/mar & $\begin{array}{l}\text { Puente, } \\
\text { basuras, } \\
\text { urbanizaciones }\end{array}$ & no & Privada \\
\hline H5 & Humedal Pachingo & $\begin{array}{l}\text { Pachingo/ } \\
\text { Tangue }\end{array}$ & IV & 05/07/2007 & 253734 & 6640627 & $\begin{array}{l}\text { Humedal-Saladar } \\
\text { permanente }\end{array}$ & 50 & 15,5 & 8,7 & 5100 & $\begin{array}{l}\text { quebrada/ } \\
\text { acuífero/ } \\
\text { pluvial }\end{array}$ & $\begin{array}{l}\text { Caminos entre } \\
\text { saladares, } \\
\text { ganadería, posible } \\
\text { vertido químico }\end{array}$ & no & Mixto \\
\hline H6 & Salinas Grande & Tongoy & IV & 05/07/2007 & 255929 & 6645493 & $\begin{array}{l}\text { Humedal litoral-Saladar } \\
\text { permanente }\end{array}$ & 30 & 18,2 & 8,73 & 37200 & mareas & $\begin{array}{l}\text { Basuras, camino } \\
\text { lateral }\end{array}$ & no & $\begin{array}{c}\text { Privada y } \\
\text { publica }\end{array}$ \\
\hline H7 & Salinas Chica & Tongoy & IV & 05/07/2007 & 259079 & 6647433 & $\begin{array}{l}\text { Humedal litoral-Saladar } \\
\text { permanente }\end{array}$ & 15 & 16 & 9,26 & 18100 & $\begin{array}{c}\text { quebrada/ } \\
\text { acuífero/ } \\
\text { pluvial }\end{array}$ & $\begin{array}{l}\text { Basuras, } \\
\text { urbanización }\end{array}$ & no & $\begin{array}{c}\text { Privada y } \\
\text { publica }\end{array}$ \\
\hline H8 & Salinas Palo Colorao & Los Vilos & IV & 06/07/2007 & 263789 & 6454727 & Laguna permanente & & 13 & 9,4 & 667 & & $\begin{array}{l}\text { No se detectan } \\
\text { impactos }\end{array}$ & no & Pública \\
\hline H9 & Salinas Pullally & Papudo & $\mathrm{V}$ & 06/07/2007 & 273390 & 6410670 & $\begin{array}{l}\text { Humedal litoral } \\
\text { permanente }\end{array}$ & & 13,5 & 7,5 & 34400 & & $\begin{array}{l}\text { Canales, } \\
\text { eucaliptos en } \\
\text { orillas, } \\
\text { caza }\end{array}$ & no & Pública \\
\hline $\mathrm{H} 10$ & Laguna Verde & Valparaíso & $\mathrm{V}$ & 07/07/2007 & 251049 & 6334375 & $\begin{array}{l}\text { Laguna litoral } \\
\text { permanente }\end{array}$ & & 10,3 & 6,15 & 1372 & & $\begin{array}{l}\text { Casas, vertidos, } \\
\text { eucaliptos, } \\
\text { basuras, } \\
\text { aterramientos }\end{array}$ & no & Pública \\
\hline
\end{tabular}


Continuación TABLA II

\begin{tabular}{|c|c|c|c|c|c|c|c|c|c|c|c|c|c|c|c|}
\hline H11 & Laguna El Peral & San Antonio & $\mathrm{V}$ & 07/07/2007 & 257508 & 6289841 & Laguna permanente & & 12 & 7,7 & 1288 & $\begin{array}{l}\text { estero } \\
\text { temporal }\end{array}$ & Casas & $\begin{array}{l}\text { Santuario } \\
\text { de la } \\
\text { Naturaleza }\end{array}$ & Pública \\
\hline H12 & Laguna Llolleo & San Antonio & $\mathrm{V}$ & 07/07/2007 & 256794 & 6278679 & $\begin{array}{l}\text { Humedal litoral } \\
\text { permanente }\end{array}$ & & 11,3 & 5,5 & 904 & & $\begin{array}{l}\text { Casas, vertidos, } \\
\text { aparcamiento en } \\
\text { orillas, basuras, } \\
\text { caminos }\end{array}$ & no & Pública \\
\hline H13 & Laguna Las Salinas & El Yali & $\mathrm{V}$ & 08/07/2007 & 248357 & 6257001 & Laguna permanente & 520,37 & 11,8 & 7,64 & 32100 & & $\begin{array}{l}\text { Ganadería, } \\
\text { eucaliptos, } \\
\text { antigua } \\
\text { explotación de sal }\end{array}$ & $\begin{array}{c}\text { Reserva } \\
\text { Nacional, } \\
\text { RAMSAR }\end{array}$ & Privado \\
\hline H14 & Tranque Los Molles & El Yali & $\mathrm{V}$ & 08/07/2007 & 250539 & 6256346 & $\begin{array}{l}\text { Laguna represada } \\
\text { permanente }\end{array}$ & & 11,7 & 8 & 2160 & & Aterramientos & $\begin{array}{c}\text { Reserva } \\
\text { Nacional, } \\
\text { RAMSAR }\end{array}$ & Privado \\
\hline H15 & Laguna Matanzas & El Yali & $\mathrm{V}$ & 08/07/2007 & 250689 & 6261241 & Laguna permanente & & 12,3 & 7,58 & 1286 & subterránea & Eucaliptos & $\begin{array}{c}\text { Reserva } \\
\text { Nacional, } \\
\text { RAMSAR }\end{array}$ & Privado \\
\hline H16 & Laguna Colejuda & El Yali & $\mathrm{V}$ & 08/07/2007 & 250102 & 6260478 & Laguna permanente & & 11,6 & 8,4 & 52200 & & $\begin{array}{l}\text { Alta presión } \\
\text { ganadera, } \\
\text { eucaliptos, agua } \\
\text { anoxica, negra }\end{array}$ & $\begin{array}{c}\text { Reserva } \\
\text { Nacional, } \\
\text { RAMSAR }\end{array}$ & Privado \\
\hline H17 & Laguna Seca & El Yali & $\mathrm{V}$ & 08/07/2007 & 248739 & 6258551 & Laguna temporal & & - & - & - & & Ganadería, casas & $\begin{array}{c}\text { Reserva } \\
\text { Nacional, } \\
\text { RAMSAR }\end{array}$ & Privado \\
\hline H17 & Laguna Cabildo & El Yali & $\mathrm{V}$ & 09/07/2007 & 251551 & 6261923 & Laguna permanente & & 10,5 & 7,6 & 12360 & subterránea & Eucaliptos & $\begin{array}{c}\text { Reserva } \\
\text { Nacional, } \\
\text { RAMSAR }\end{array}$ & Privado \\
\hline H18 & Laguna del Rey & El Yali & $\mathrm{V}$ & 09/07/2007 & 246137 & 6255338 & Laguna permanente & & 13,2 & 7,1 & 6780 & subterránea & Ganadería & $\begin{array}{c}\text { Reserva } \\
\text { Nacional, } \\
\text { RAMSAR }\end{array}$ & Privado \\
\hline H19 & Laguna Guairao & El Yali & $\mathrm{V}$ & 09/07/2007 & 249389 & 6259933 & Laguna permanente & & 10,9 & 7,3 & 1350 & subterránea & Eucaliptos & $\begin{array}{c}\text { Nacional, } \\
\text { Reserva } \\
\text { RAMSAR }\end{array}$ & Privado \\
\hline
\end{tabular}


TABLA II. Unidades de vegetación palustre y acuática detectadas en los humedales estudiados.

TABLE II. Units marsh and aquatic vegetation found in wetlands studied.

\begin{tabular}{|c|c|c|c|c|c|c|c|c|c|c|}
\hline & \multirow{2}{*}{\multicolumn{6}{|c|}{ Unidades de vegetación }} & \multirow{2}{*}{\multicolumn{4}{|c|}{ Macrófitos }} \\
\hline & & & & & & & & & & \\
\hline & Salinas & Tifales & Carrizos & Juncales & Juncales-Salinas & Molle & Ranunculáceas & Apiáceas Lemnáceas & Ceratofiláceas Pontederiáceas & Cianofíceas \\
\hline Punta Teatinos/Saladita & $\sqrt{ }$ & $\sqrt{ }$ & & & & & & & & \\
\hline Humedal La Serena & $\sqrt{ }$ & $\sqrt{ }$ & & & & & & & & \\
\hline Humedal Coquimbo/Estero Culebrón & $\sqrt{ }$ & $\sqrt{ }$ & & $\sqrt{ }$ & & & & $\sqrt{ }$ & $\sqrt{ }$ & \\
\hline Laguna Adelaida/Lagunillas & $\sqrt{ }$ & $\sqrt{ }$ & $\sqrt{ }$ & $\sqrt{ }$ & & & & & & \\
\hline Humedal Pachingo & $\sqrt{ }$ & $\sqrt{ }$ & & & $\sqrt{ }$ & & & & & \\
\hline Salinas Grande & $\sqrt{ }$ & & $\sqrt{ }$ & & & & & & & \\
\hline Salinas Chica & $\sqrt{ }$ & & & $\sqrt{ }$ & & & & & & \\
\hline Salinas Palo Colorao & & & & & & & & & $\sqrt{ }$ & \\
\hline Salinas Pullally & $\sqrt{ }$ & & & & & & & & & \\
\hline Laguna Verde & & & & & & & & $\sqrt{ }$ & & \\
\hline Laguna El Peral & & & & $\sqrt{ }$ & & & & & $\sqrt{ }$ & \\
\hline Laguna Llolleo & & & $\sqrt{ }$ & & & & & & & \\
\hline Laguna Las Salinas & $\sqrt{ }$ & & & & & & & & & \\
\hline Tranque Los Molles & & & & $\sqrt{ }$ & & $\sqrt{ }$ & & & $\sqrt{ }$ & \\
\hline Laguna Matanzas & & & & $\sqrt{ }$ & & & & & & $\sqrt{ }$ \\
\hline Laguna Colejuda & & & & & & $\sqrt{ }$ & & & & \\
\hline Laguna Seca & $\sqrt{ }$ & & & & & & & & & \\
\hline Laguna Cabildo & & & & $\sqrt{ }$ & & $\sqrt{ }$ & & & & $\sqrt{ }$ \\
\hline Laguna del Rey & & & & $\sqrt{ }$ & & & & & & \\
\hline Laguna Guairao & & & & $\sqrt{ }$ & & & $\sqrt{ }$ & & & \\
\hline
\end{tabular}

Punta Teatinos/Saladita

Humedal La Serena

aguna Matanzas

Laguna Cabildo

Laguna Guairao 
El jacinto de agua (Eichhornia crassipes (Mart.) Solms.), se detectó en el Humedal de Coquimbo. Se trata de una especie invasora cuyo origen son los cursos de agua de la cuenca del Amazonas en América de Sur. Es un macrófito flotante de raíces sumergidas, con una fácil reproducción vegetativa y sexual. Actualmente se encuentra distribuido prácticamente por todo el mundo, dado que su aspecto ornamental originó su exportación a estanques y láminas acuáticas de jardines en climas templados y cálidos. Su crecimiento desmesurado tapona y obstruye en poco tiempo una vía fluvial o lacustre. Como consecuencia de su proliferación crea importantes problemas en ríos y lagos, canales de riego, ecosistemas ribereños, ya que cubre como una manta toda la superficie de la lámina de agua. Esta especie está considerada entre las 100 especies más invasoras del mundo por la UICN (2007).

En relación con los invertebrados acuáticos, en la Tabla III, se presenta el listado de taxones recogidos en el total de humedales prospectados. Casi todos los organismos se han identificado al nivel taxonómico más bajo posible, siendo el nivel de familia el más recurrente. La comunidad de invertebrados acuáticos de los humedales estudiados está compuesta por 42 taxa correspondientes a 29 familias. Los insectos es el grupo más diversificado con 17 familias y dentro de ellos, los dípteros representado con 8 familias y 11 taxa. Los grupos más abundantes: insectos, crustáceos y moluscos, son resumidos en la Tabla IV, donde se incluyen nemátodos, planarias, oligoquetos e hirudíneos. Punta Teatinos, las Salinas de Palo Colorao y el Tranque de Molles, son los humedales que presentan mayor número de taxones $(15,13$ y 14 , respectivamente). Por el contrario, no se ha encontrado ninguno en las lagunas Llolleo, Colejuda y Seca (la última sin agua). Punta Teatinos, es el humedal con mayor número de familias de insectos (8), pero las dos especies de efemerópteros recolectadas sólo se encuentran en las Salinas de Palo Colorao. De los 3 taxones de odonatos recolectados, como máximo se presentan dos en cinco humedales (La Serena, Adelaida, Salinas Palo Colorao, Laguna El Peral y Tranque Los Molles). Sólo se ha recolectado una familia de tricópteros que se presenta en las Salinas de Palo Colorao. Las dos familias de hemípteros, se presentan en las lagunas del Rey y Guairao y finalmente, de las 8 familias de dípteros recogidas, cinco como máximo se recolectan en Punta Teatinos y 4 en la Laguna Cabildo.
Un análisis exploratorio mediante correlación (Pearson) entre las variables ambientales evaluadas y el número de taxa $(\mathrm{p}<0,05)$ permitió observar que esta no se correlaciona bien con la temperatura $(\mathrm{r}=0,06)$, baja con el $\mathrm{pH}(\mathrm{r}=0,33)$, mientras que muestra una buena correlación con la conductividad $(\mathrm{r}=0,57$; Figura 3). Respecto del índice ECELS, este presentó una correlación baja $(\mathrm{r}=0,30)$.

En cuanto a la fauna piscícola, se han recolectado un total de cuatro especies: lisa (Mugil cephalus, Linnaeus), gambusia (Gambusia holbrooki, Girard), gambusia manchada o madrecita (Cnesterodon decemmaculatus, Jenyns), y chanchito (Cichlasoma facetum, Jenyns). Las tres últimas son exóticas, mientras que $M$. cephalus, es una especie marina que ocasionalmente se integra en las aguas continentales chilenas a desarrollar parte de su ciclo vital. Ninguna de las especies de peces recolectadas está catalogada como amenazada por la UICN (2007). En la Tabla IV, se presentan los datos sobre su distribución en los humedales estudiados.

La lisa es una especie catádroma facultativa con una gran capacidad osmorregulatoria (Riede 2004), la cual puede remontar hasta $50 \mathrm{~km}$ aguas arriba en los ríos andinos de Chile (Habit 1998). Tolera amplios rangos de salinidad y temperatura, además de cierta contaminación orgánica de las aguas. Habita preferentemente los cursos bajos de los ríos y estuarios. Su dieta es preferentemente fitófaga e iliófaga. La reproducción sucede en zonas costeras entre los meses de junio y agosto. Las hembras llegan a desovar millones de huevos flotantes que dan lugar a alevines de crecimiento muy rápido. Tiene cierta importancia comercial, por el consumo de su carne y de sus huevos (caviar de mújol) (Smith 1997). Es una especie circumtropical, pero también presente en muchas regiones templadas (hasta la isoterma de $15^{\circ} \mathrm{C}$ ). En la costa pacífica americana se extiende desde California (U.S.A.) a Chile, incluyendo el Golfo de California y las Islas Galápagos (Thomson 1990; Eschmeyer et al. 1983). En este trabajo se ha recolectado en los Humedales de La Serena y Coquimbo.

La gambusia es la especie con la más amplia distribución en los humedales estudiados; habita cualquier tipo de curso o cuerpo de agua, siempre y cuando no presente salinidades muy elevadas, aunque Salibian (1977) comprueba que en cautiverio es capaz de tolerar, hasta por una semana, salinidades de 17,19 g/l. Tolera desde aguas típicas de arroyo de montaña de zonas cálidas hasta aguas 
muy contaminadas (vertidos de aguas residuales), con elevadas temperaturas y bajas concentraciones de oxígeno disuelto (Chervinski 1983), cualidades que le permiten ocupar hábitats vedados para otras especies. Su enorme potencial biológico, que la hace ser especie dominante en la mayoría de estos hábitats, ha llevado al borde de la desaparición a numerosas especies endémicas (Milton \& Arthington 1983). Estudios de competencia realizados actualmente han demostrado que desplaza a los ciprinodóntidos y que es una de las principales causas de que en la actualidad se encuentren "En Peligro de Extinción”. Según la UICN (2007) se encuentra entre las 100 especies más invasoras a nivel global.

La gambusia manchada es una especie autóctona de Argentina y Brasil fue introducida en aguas chilenas desde Argentina (Welcomme 1988). Es muy valorada en acuariofilia. Su tamaño no excede de $5 \mathrm{~cm}$ de longitud. Habita cualquier tipo de cuerpo de agua, siempre y cuando no presente salinidades muy elevadas. Su dieta se basa en crustáceos, pequeños moluscos, larvas, insectos y huevos y/o alevines de otros peces. Su hábitat es muy amplio, citándose en casi todos los ambientes de agua dulce. Se ha recolectado en las Laguna de Matanzas y del Rey, en el Complejo del Yali.

El chanchito, es una especie autóctona de Argentina, Brasil y Uruguay y al igual que la gambusia manchada, fue introducida en aguas chilenas desde Argentina (Ruiz \& Marchant 1989). Su tamaño es mediano y no supera los $25 \mathrm{~cm}$ de longitud total. Habita ríos, lagunas y ambientes artificiales en zonas de poca profundidad. Esta especie desova sobre sustrato duro; tras la puesta, los huevos y alevines son cuidados por ambos padres. La dieta incluye insectos, copépodos, cladóceros, larvas de quironómidos, gastrópodos y anfípodos. En este trabajo solamente fue recolectada en el Humedal de Coquimbo.

\section{Estado De Conservación De Los Humedales}

En la Tabla I, se presentan los impactos detectados y algunos datos sobre el estado de conservación y sobre la propiedad de los humedales estudiados. Los impactos humanos son variados, las basuras son visibles en la mayor parte de ellos y la presión humana por urbanizaciones, incluyendo pequeños vertidos orgánicos, son también habituales. No se ha detectado ningún impacto en las Salinas de Palo Colorao. El complejo del Yali, presenta impactos importantes debido a la transformación del uso del suelo para la plantación de Eucaliptus, que en algunos casos altera significativamente la calidad del agua, reduciendo el rendimiento hídrico de las cuencas.

De los humedales estudiados, sólo dos presentan algún tipo de protección: El complejo del Yali que es Reserva Nacional y humedal Ramsar y la Laguna El Peral que tiene la categoría de Santuario de la Naturaleza. Aunque no se ha podido encontrar información sobre la propiedad de los humedales estudiados, muchos de ellos son de propiedad privada. De hecho, en el humedal de La Laguna de Conchalí, Ramsar, no fue posible muestrear al no disponer del permiso de la Sociedad Minera Los Pelambres, que es su propietario actual. Para establecer el estado de conservación de los humedales estudiados, se aplicó el Índice del Estado de Conservación de Ecosistemas Leníticos Someros (ECELS), propuesto por la Agencia Catalana del Agua (2004).

En la Tabla V, se presentan los resultados de su aplicación a los humedales estudiados. Los valores máximos para el bloque 1, se obtuvieron en 6 de ellos (Punta Teatinos, Pachingo, El Peral, Las Salinas, Colejuda y Laguna Seca), mientras que en 10 de ellos hubo que aplicarles la corrección. Para el bloque 2, el valor máximo se obtuvo en las salinas de Palo Colorao, mientras que a 12 de ellos se les aplicó un modulador. Infraestructuras de distinto tipo se detectaron en 16 de los 20 humedales estudiados y casas o urbanizaciones en el entorno, en 16 de ellos. Basuras y restos orgánicos también se detectaron en buena parte de los humedales. Para el bloque 3, que se refiere al aspecto del agua, obtuvieron el valor máximo los humedales de Coquimbo, Pachingo, Salinas Palo Colorao y el Peral. En la mitad de los humedales estudiados, se obtuvo la máxima puntuación (30 puntos) para el bloque 4. Sin embargo, en dos de ellos pertenecientes al complejo del Yali (Laguna Colejuda y Seca) el valor para este bloque fue de 0 puntos, debido a la sustitución de la vegetación ribereña por plantaciones de Eucaliptus. Para el bloque 5, el máximo de 20 puntos se obtuvo para tres humedales (Salinas de Palo Colorao, Laguna de El Peral y Tranque Los Molles). En 12 de los 20 humedales estudiados la puntuación fue de 0 puntos. El valor final, se obtiene de la suma de los bloques. Dos humedales (Laguna de El Peral y Las Salinas) obtuvieron la máxima calidad. En 5 humedales la calidad fue buena, en 7 de ellos la calidad fue media y en 6 la calidad fue mala (5 humedales) o muy mala (1 humedal). 
TABLA III. Listado general de los taxa de invertebrados acuáticos recolectados en los humedales estudiados.

TABLE III. Aquatic invertebrates taxa collected in the wetlands studied.

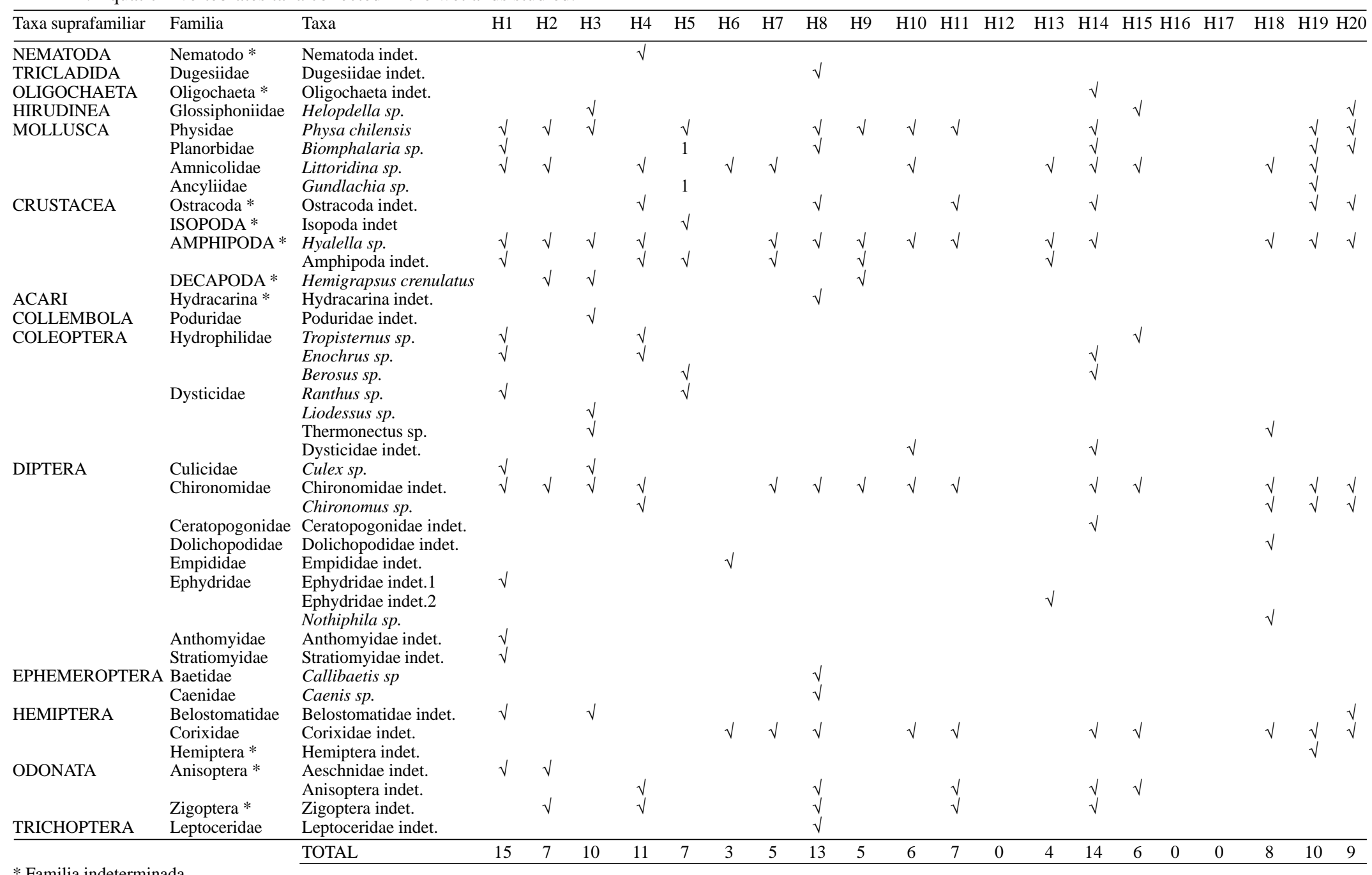


TABLa IV. Distribución de los grupos de invertebrados acuáticos y de peces recolectados en los humedales prospectados.

TABLE IV. Distribution of invertebrate aquatic groups and fish collected from prospective wetlands.

\begin{tabular}{|c|c|c|c|c|c|c|c|c|c|}
\hline \multirow[b]{2}{*}{ Localidad } & \multicolumn{6}{|c|}{ Invertebrados } & \multicolumn{3}{|c|}{ Peces } \\
\hline & Otros & Moluscos & Crustáceos & Insectos & TOTAL & Mugil cephalus & Gambusia holbrooki & Cnesterodon decemmaculatus & Cichlasoma facetum \\
\hline Punta Teatinos/Saladita & 0 & 3 & 2 & 10 & 15 & & & & \\
\hline Humedal La Serena & 0 & 2 & 2 & 3 & 7 & $\sqrt{ }$ & $\sqrt{ }$ & & \\
\hline Humedal Coquimbo/Estero Culebrón & 1 & 1 & 2 & 6 & 10 & $\sqrt{ }$ & $\sqrt{ }$ & & $\sqrt{ }$ \\
\hline Laguna Adelaida/Lagunillas & 1 & 2 & 3 & 5 & 11 & & $\sqrt{ }$ & & \\
\hline Humedal Pachingo & 0 & 3 & 2 & 2 & 7 & & & & \\
\hline Salinas Grande & 0 & 1 & 0 & 2 & 3 & & & & \\
\hline Salinas Chica & 0 & 1 & 2 & 2 & 5 & & & & \\
\hline Salinas Palo Colorao & 1 & 2 & 2 & 8 & 13 & & & & \\
\hline Salinas Pullally & 0 & 1 & 3 & 1 & 5 & & & & \\
\hline Laguna Verde & 0 & 2 & 1 & 3 & 6 & & & & \\
\hline Laguna El Peral & 0 & 1 & 2 & 4 & 7 & & $\sqrt{ }$ & & \\
\hline Laguna Llolleo & 0 & 0 & 0 & 0 & 0 & & & & \\
\hline Laguna Las Salinas & 0 & 1 & 2 & 1 & 4 & & $\sqrt{ }$ & & \\
\hline Tranque Los Molles & 1 & 3 & 2 & 8 & 14 & & & & \\
\hline Laguna Matanzas & 1 & 1 & 0 & 4 & 6 & & $\sqrt{ }$ & $\sqrt{ }$ & \\
\hline Laguna Colejuda & 0 & 0 & 0 & 0 & 0 & & & & \\
\hline Laguna Seca & 0 & 0 & 0 & 0 & 0 & & & & \\
\hline Laguna Cabildo & 0 & 1 & 1 & 6 & 8 & & & & \\
\hline Laguna del Rey & 0 & 4 & 2 & 4 & 10 & & & $\sqrt{ }$ & \\
\hline Laguna Guairao & 1 & 2 & 2 & 4 & 9 & & & & \\
\hline
\end{tabular}


Tabla V. Resultados de la aplicación de Indice del Estado de Conservación de los Ecosistemas Lénticos (ECELS) a los humedales estudiados.

TABLE V. Results of the application of Conservation State of Ecosystem Lentic Index (ECELS) to wetlands studied.

\begin{tabular}{|c|c|c|c|c|c|c|c|c|c|c|c|c|c|c|c|c|c|c|c|c|c|c|c|c|c|c|}
\hline Código & pendiente & Modulador & total & corregido & hidráulicas & viarias & inmuebles & usos & Modulador & total & corregido & transparencia & olor & total & corregido & perimetro & humedal & Modulador & total & corregido & $\begin{array}{l}\text { Vegetación } \\
\text { sumergida }\end{array}$ & $\begin{array}{l}\text { Vegetación } \\
\text { flotante }\end{array}$ & Modulador & total & corregido & TOTAL \\
\hline H1 & 20 & & 20 & 20 & 5 & 3 & 5 & 3 & -16 & 0 & 0 & 2 & 5 & 7 & 7 & 10 & 10 & 20 & 40 & 30 & 5 & 0 & & 5 & 5 & 62 \\
\hline $\mathrm{H} 2$ & 0 & -5 & -5 & 0 & 5 & 5 & 5 & 3 & -13 & 5 & 5 & 2 & 5 & 7 & 7 & 10 & 10 & 20 & 40 & 30 & 5 & 3 & & 8 & 8 & 50 \\
\hline $\mathrm{H} 3$ & 10 & -10 & 0 & 0 & 5 & 0 & 0 & 5 & -15 & -5 & 0 & 5 & 5 & 10 & 10 & 10 & 15 & 20 & 45 & 30 & 5 & 3 & -10 & -2 & 0 & 40 \\
\hline $\mathrm{H} 4$ & 5 & -5 & 0 & 0 & 5 & 0 & 5 & 1 & -3 & 8 & 8 & 0 & 5 & 5 & 5 & 10 & 15 & 15 & 40 & 30 & 5 & 3 & & 8 & 8 & 51 \\
\hline H5 & 20 & & 20 & 20 & 5 & 3 & 5 & 0 & 1 & 14 & 14 & 5 & 5 & 10 & 10 & 15 & 5 & 20 & 40 & 30 & 0 & 0 & & 0 & 0 & 74 \\
\hline H6 & 10 & & 10 & 10 & 5 & 3 & 5 & 5 & -5 & 13 & 13 & 0 & 5 & 5 & 5 & 10 & 15 & 20 & 45 & 30 & 5 & 0 & 5 & 10 & 10 & 68 \\
\hline H7 & 0 & -10 & -10 & 0 & 5 & 3 & 5 & 5 & -10 & 8 & 8 & 0 & 5 & 5 & 5 & 15 & 0 & 20 & 35 & 30 & 5 & 0 & -5 & 0 & 0 & 43 \\
\hline $\mathrm{H} 8$ & 0 & -15 & -15 & 0 & 0 & 5 & 5 & 5 & 5 & 20 & 20 & 5 & 5 & 10 & 10 & 0 & 0 & 10 & 10 & 10 & 10 & 0 & 10 & 20 & 20 & 60 \\
\hline $\mathrm{H} 9$ & 10 & -10 & 0 & 0 & 5 & 3 & 5 & 1 & -3 & 11 & 11 & 0 & 5 & 5 & 5 & 10 & 0 & 10 & 20 & 20 & 0 & 0 & & 0 & 0 & 36 \\
\hline H10 & 10 & -15 & -5 & 0 & 0 & 0 & 0 & 1 & -13 & -12 & 0 & 0 & 5 & 5 & 5 & 0 & 0 & 0 & 0 & 0 & 0 & 3 & -5 & -2 & 0 & 5 \\
\hline H11 & 20 & & 20 & 20 & 5 & 5 & 0 & 5 & 0 & 15 & 15 & 5 & 5 & 10 & 10 & 10 & 15 & 5 & 30 & 30 & 10 & 3 & 10 & 20 & 20 & 95 \\
\hline H12 & 0 & -15 & -15 & 0 & 0 & 3 & 0 & 0 & -13 & -10 & 0 & 0 & 5 & 5 & 5 & 5 & 0 & 10 & 15 & 15 & 0 & 0 & & 0 & 0 & 20 \\
\hline $\mathrm{H} 13$ & 20 & -5 & 15 & 15 & 5 & 5 & 3 & 3 & -3 & 13 & 13 & 2 & 5 & 7 & 7 & 0 & 15 & 15 & 30 & 30 & 5 & 0 & 10 & 15 & 15 & 80 \\
\hline H14 & 10 & -5 & 5 & 5 & 5 & 3 & 5 & 1 & -2 & 12 & 12 & 2 & 5 & 7 & 7 & 5 & 15 & 30 & 50 & 30 & 10 & 5 & 10 & 25 & 20 & 74 \\
\hline H15 & 5 & & 5 & 5 & 5 & 5 & 5 & 0 & & 15 & 15 & 0 & 5 & 5 & 5 & 15 & 0 & 10 & 25 & 25 & 0 & 0 & & 0 & 0 & 50 \\
\hline H16 & 20 & & 20 & 20 & 0 & 5 & 5 & 1 & & 11 & 11 & 0 & 5 & 5 & 5 & 0 & 0 & 0 & 0 & 0 & 0 & 0 & & 0 & 0 & 36 \\
\hline H17 & 20 & & 20 & 20 & 5 & 0 & 3 & 3 & -3 & 8 & 8 & & 5 & 5 & 5 & 0 & 0 & -5 & -5 & 0 & 0 & 0 & & 0 & 0 & 33 \\
\hline H17 & 5 & & 5 & 5 & 5 & 5 & 3 & 1 & & 14 & 14 & 0 & 5 & 5 & 5 & 5 & 0 & 0 & 5 & 5 & 0 & 0 & & 0 & 0 & 29 \\
\hline H18 & 10 & & 10 & 10 & 5 & 5 & 5 & 3 & & 18 & 18 & 0 & 5 & 5 & 5 & 5 & 0 & 10 & 15 & 15 & 0 & 0 & & 0 & 0 & 48 \\
\hline H19 & 10 & & 10 & 10 & 5 & 5 & 5 & 1 & & 16 & 16 & 0 & 5 & 5 & 5 & 5 & 0 & 10 & 15 & 15 & 0 & 0 & & 0 & 0 & 46 \\
\hline
\end{tabular}




\section{DISCUSION}

La diversidad bioclimática de Chile genera una gran variedad de ambientes acuáticos. Los lagos y lagunas de la zona central se caracterizan por ser altamente productivos, de escasa profundidad, con vegetación ribereña alta casi en todo su perímetro y abundante vegetación sumergida (Riveros et al. 1981). Aquellos más cercanos a la costa pueden tener una mayor influencia marina, ricos en materia orgánica y de menor profundidad, aumentando la diversidad de hábitat. De acuerdo a la estrategia nacional para la conservación de los humedales, impulsada por CONAMA (2005), uno de los principales problemas es la tipificación o clasificación de estos sistemas de acuerdo a sus características naturales, situación que resulta muy difícil de abordar cuando existe muy poca información respecto a sus características hidroquímicas, su relación general con el medio donde se inserta, características biológicas en términos de funcionalidad (e.g. relación entre su biota acuática y ribera) y muy especialmente, el nivel de presión a que han sido sometidos por el incremento del desarrollo urbano que ha provocado la mayor destrucción de estos ambientes en el mundo (Gallego et al. 1999; Semlitsch \& Bodie 1998). A pesar de la importancia, en Chile existen muy pocos trabajo sobre caracterización y valoración de estos sistema y en general, corresponden a inventarios (e.g. González $\&$ Victoriano 2005). Un reciente trabajo de VillagránMella et al. (2006), aborda un carácter más funcional y relaciona características de presión de humedales urbanos de la intercomunal Concepción- TalcahuanoSan Pedro con la fauna de insectos acuáticos.

En este estudio entregamos una primera aproximación a los humedales de la zona mediterránea norte de Chile en un gradiente latitudinal, que permite ver la variabilidad que presentan estos cuerpos de aguas, según se refleja en los valores de $\mathrm{T}^{\mathrm{a}}, \mathrm{pH}$ y especialmente, en la conductividad del agua, que es determinante en la composición florística y faunística de cada una de ella. Al respecto se observa que las formaciones vegetacionales son pobres en diversidad y están relacionadas con la salinidad que presenta cada uno de los humedales, siendo característicos las formaciones de Sarcocornia y Spartina en los sectores más salinos y con características estuarinas, lo cual ha sido estudiado por Figueroa \& Valdovinos (1997), como vegetación dominante. Mientras que sectores con influencia de aguas más dulces permite el desarrollo de cordones litorales de juncales y tifales.
Aquellos que muestran un claro efecto de la presión urbana tienen un mayor desarrollo de plantas flotantes Eichhornia crassipes, mientras que en otros sistemas más cerrados, con baja circulación y que actúan como depósitos del material orgánico proveniente de sus riberas (agricultura y plantaciones de pino), es posible observar toda su superficie de color verde intenso proporcionado por la abundante biomasa de Anabaena. Finalmente, en aquellos de agua dulce y en mejor estado de conservación es común observar Ceratophilium chilensis. Esta información es coincidente con lo reportado por Ramírez \& San Martín (2006) quien hace una buena aproximación al uso de las plantas acuáticas como indicadoras de calidad ecológica. Es importar señalar que aquellos cuerpos que son rodeados por vegetación nativa (e.g. Molles) presentan un buen estado de conservación, a pesar de la presión del uso agrícola que pueda existir en sus alrededores. Esto es relevante de destacar en planes de conservación y manejo de humedales o fiscalización de todos los cuerpos acuáticos de Chile, pues existe la urgente necesidad de la protección de riberas para la conservación de la diversidad acuática y terrestre asociada, y que sólo pasa por el cumplimiento de leyes y adecuada fiscalización (Pellet et al. 2005) pudiendo de esta forma compensar en parte la presión que se ejerce sobre cada microcuenca.

Respecto de la fauna de invertebrados, se detectó un total de 42 taxa, distribuidos en 29 familias. De estas familias 17 son insectos, lo cual se considera elevado en comparación con otros sistemas similares. Villagrán-Mella et al. (2006), define un total de 21 familias para 7 humedales de Concepción, en un estudio con mayor intensidad o esfuerzo de muestreo (30 puntos de muestreos por humedal). Sin embargo, incluye en su estudio grupos que no son reconocidos como acuáticos (e.g. Cicadellidae (Hemiptera), Carabidae y Scirtidae (Coleoptera)), pero no detectan efemerópteros, y al menos dos familias de baja exigencia ambiental como Baetidae y Caenidae, son comunes y factibles de encontrar en un sistema bien conservado como Laguna Verde en la Península de Hualpén. Si se debe indicar que la diversidad de todos los sistemas es muy baja comparada con cualquier sistema fluvial, es así como en el trabajo de Figueroa et al. (2006) se hace mención a 92 taxa encontrados en $5 \mathrm{~km}$ del río Nonguén, 56 taxa para el Río Itata, 108 para el río Biobío y 77 taxa en el río Damas los cuales por su funcionamiento (alta tasa de renovación del agua, flora y fauna típica asociada, mayor 
concentración de valores naturales de oxígeno, baja conductividad, etc.) no pueden ser incluidos como humedales típicos, entendidos como depresiones del terreno que permiten el desarrollo de una vegetación típica y fauna asociada.

El análisis de los datos obtenidos indica que la riqueza de invertebrados presenta una baja correlación con las variables, temperatura y $\mathrm{pH}$, mientras que tiene una buena correlación con la conductividad. Al respecto, los invertebrados han sido utilizados como indicadores de calidad de ecosistemas acuáticos inclusive con aplicaciones en Chile (Figueroa et al. 2003, 2006, 2007), no obstante, no puede utilizarse un criterio similar en sistemas de humedales, sin ajuste previo y un amplio conocimiento sobre la presencia versus variables ambiental, puesto que los taxa comunes son aquellos que han sido identificados como "muy tolerantes" en sistemas fluviales y naturalmente, propios en sistemas más complejos y extremos como los humedales. Estas mismas condiciones permiten el desarrollo de abundantes poblaciones de grupos tolerantes a las variaciones de salinidad (e.g. anfípodos) y la ausencia de otros menos tolerantes, y que no necesariamente indican un sistema alterado. Esto puede apreciarse en la baja correlación que existe entre la riqueza de taxa y el ECELS, que evalúa la naturalidad del sistema.

La fauna íctica de las regiones IV y V está formada por un total de 31 especies, de las cuales 14 son autóctonas (el 78\% de ellas son endémicas), 9 exóticas y 8 ocasionales. De la revisión de Campos et al. (1998) se concluye que este grupo de vertebrados presenta importantes problemas de conservación. La amenaza biológica de mayor impacto es el efecto que ejercen las especies exóticas sobre la ictiofauna nativa. En efecto, la introducción de especies exóticas en ecosistemas que no corresponden a su rango nativo de distribución, es uno de los mayores riesgos para la pérdida de biodiversidad (Clavero \& GarcíaBerthou 2005). Los efectos nocivos que causan estas especies son un problema de repercusión mundial, que puede tener consecuencias catastróficas a distintos niveles de la escala natural. De hecho, pueden modificar los hábitats por completo, desplazando y reemplazando a especies nativas (GEIB 2006).

Los efectos concretos que provocan las especies exóticas no han sido estudiados en los humedales de Chile (Campos 1970), no obstante, las interacciones genéricas que han sido descritas en otros estudios son aplicables a estos espacios, como predación sobre las poblaciones de zooplancton y macroinvertebrados bentónicos, lo que se traduce en cambios importantes de la comunidad, con posibles explosiones de fitoplancton, alterando en definitiva la calidad del agua. Además pueden ejercer un efecto dañino depredando macroinvertebrados de interés conservacionista y sobre puestas y/o larvas de peces autóctonos, prácticamente ausente en estos sistemas.

Gambusia holbrooki, especie con mayor presencia en las zonas someras de los humedales mediterráneos de Chile, figura en la lista de las 100 especies invasoras más dañinas según la ISSG (Invasive Species Specialist Group) de la UICN. Las características que han propiciado la pertenencia de la especie a este ranking mundial son principalmente su amplia tolerancia ambiental, su condición de depredador generalista y su corto período generacional. Según Courtenay \& Meffe (1989), G. holbrooki presenta una gran capacidad de éxito como especie invasora debido a su reproducción muy especializada y exitosa (alta fecundidad, rápido desarrollo juvenil, período reproductor prolongado y con múltiples desoves, rápida madurez sexual con menos de 3 meses de vida, escasa exigencia en relación a la temperatura y fotoperíodo para la reproducción; etc.); y a su agresividad elevada en las hembras, incluso causando la muerte de macroinvertebrados (Leyse et al. 2003), de otras especies de peces, e incluso de anfibios (Baber \& Babbit 2003). No obstante, gambusia, el chanchito y la gambusia manchada son especies exitosas en diversos ambientes, tan extremos como los humedales que presentan amplios rangos de salinidad, materia orgánica y bajo oxígeno, que pueden ser un problema para las especies nativas. Inclusive ya se han descrito como un problema en otros lugares de Chile, donde las condiciones no son extremas, pero su éxito adaptativo desplaza la fauna local (Ruiz \& Marchant 1989).

Es interesante señalar la baja diversidad encontrada, tanto en vegetación acuática, invertebrados y de peces, cuando la mayoría de los estudios indican lo contrario. Esto es debido que muchos de ellos se concentran en aves, por ejemplo 115 especies de Victoriano et al. (2006) y se supone una condición energética excepcional para la mantención de estas poblaciones. Esto guarda relación en parte con el tamaño del humedal (Paracuellos 2005) y el grado de protección en que se encuentra, donde estos organismos encuentran refugio y alimentación. Pero este mismo autor señala, que la mayoría de los humedales son pequeños y suelen estar intercalados 
con otros grandes, y la pérdida de humedales pequeños implica una mayor distancia entre los restantes supervivientes y por ende, disminuye la posibilidad de supervivencia a nivel metapoblacional.

Las necesidades reales de conservación no son el incremento de diversidad a escala local, como lo puede ser un humedal con alguna medida de protección, sino salvaguardar especies amenazadas que se logra con la extensión de parches diponibles, en este caso, protección de todos los humedales disponibles y por otro lado, de la funcionalidad de los mismos que aseguran la mantención de la estructura biológica los servicios ambientales que ejercen, como: recarga de acuiferos; control de inundaciones; filtros y degradadores de contaminantes; sumideros de gases de efectos invernaderos; uso de sus productos que en algunos países puede llegar a ser muy relevante en la alimentación y economía local; componente estético y cultural; entre otros.

Este trabajo es una aproximación macro, que permite identificar el grado de conservación de los humedales a través del ECELS, que evalua aspectos relevantes de la morfología del humedal, tipo y distribución y diversidad de vegetación que determina hábitat disponibles; construcciones, infraestructuras, usos humanos y aspecto del agua que determinan presiones. De modo que entrega una visión de gestión y es una herramienta de evaluación integrada del estado actual y medidas que se tomen en términos de restauración y/o protección de estas microcuencas urbanas, las cuales en general, presentan una pobre calidad de sus aguas debido a procesos de eutrofización ( Dorioz et al. 1998; Wernick et al. 1998; Wahl et al. 1997) y la contaminación ambiental de una variedad de fuentes (Lee \& Bang 2000; Fisher et al. 1999; Holland et al. 1995), inclusive aquellos bajo figuras de protección. Es probable se requiera un ajuste a la diversidad de humedales y de una calibración con caracteriscas de calidad de agua y de fauna asociada, siendo este estudio una primera aproximación.

\section{AGRADECIMIENTOS}

Este estudio fue financiado por la Agencia de Cooperación Internacional Iberoamérica. Referencias: A/5162/06 y A/010142/07. Se agradece al Centro Eula-Chile, de la Universidad de Concepción por el apoyo en infraestructura y apoyo logístico prestado. A la corporación Nacional Forestal
CONAF V, por permitirnos realizar investigación en los humedales bajo su protección.

\section{BIBLIOGRAFIA}

Agencia Catalana Del Agua. 2004. Caracterizació, regionalització i elaboració d'eines d'establiment de l'estat ecologic de les zones humides de Catalunya. Generalitat de Cataluña. 86 pp.

BABER, M.J. \& BABBIT, K.J. 2003. The relative impacts of native and introduced predatory fish on a temporary wetland tadpole assemblage. Oecologia 136:289295.

Bain, M.K. \& Stevenson, N.J. (Eds.). 1999. Aquatic Habitat Assessment: Common methods. American Fisheries Society. Bethesda, Maryland.

BOAVIDA, M.J. 1999. Wetlands: Most relevant structural and functional aspects. Limnetica17:57-63.

Campos, H. 1970. Introducción de especies exóticas y su relación con los peces de agua dulce de Chile. Noticiario del Museo Nacional de Historia Natural de Chile 14 (162):3-9.

Campos, H., Dazarola, G., Dyer, B., Fuentes, L., Gavilán J.F., Huaquín, L., Martínez, G., Meléndez, R., Pequeño, G., Ponce, F., Ruiz, V.H., Siefeld, W., Soto, D., Vega, R. \& VILA, I. 1998. Categorías de Conservación de peces nativos de aguas continentales de Chile. Boletín del Museo Nacional de Historia Natural 47:101-122.

Castro, T.B., Fajardo, G., Castro, M. \& Castro, G.M. 2006. A biometric and ecologic comparison between Artemia from México and Chile. Saline Systems 2:1-10.

Chervinski, J. 1983. Salinity tolerance of the mosquito fish, Gambusia affinis (Baird and Girard). Journal of Fish Biology 22:9-11.

Clavero, M. \& García-Berthou, E. 2005. Invasive species are leading cause of animal extinctions. Trends in ecology and evolution $20 n^{\circ} 3$, Marzo 2005.

ConAma 2002. Estrategia regional y plan de acción de la biodiversidad. IV Región Coquimbo. Comisión Nacional de Medio Ambiente. Gobierno de Chile.

ConAma 2004. Estrategia para la conservación de la biodiversidad en la Región Metropolitana de Santiago. Comisión Nacional de Medio Ambiente. Gobierno de Chile.

CONAMA 2005. Estrategia nacional para la conservación y uso racional de los humedales en Chile. Comisión Nacional de Medio Ambiente. Gobierno de Chile.

Courtenay, W.R. \& MefFe, G.K. 1989. Small fishes in strange places: A review of introduced Poeciliids. pp: 319- 332. In: Ecology and Evolution of livebearing fishes (Poeciliidae). Meffe GK \& Snelson FF (Eds). Prentice Hall (Ed). U.S.A.

Crespo, J.E. \& Baessolo, L.A. 2002. Biogeografía y taxonomia del género Artemis (Crustacea, Anostraca) en Chile: una revisión. Historia Natural I (4):17-21. 
Humedales de la zona semiárida chilena: FIgUEROA, R. ET AL.

Dominguez, E., Molineri, C., Pescador, M., Hubbart, M. \& NieTo, C. 2006. Aquatic Biodiversity in Latin America: Ephemeroptera of South America. PENSOF, Sofia, Moscow. 646 pp.

Dorioz, J.M., Casell, E.A., Orand, A. \& Eisenman, K.G. 1998. Phosphorus storage, transport and export dynamics in the Foron River Watershed. Hydrological Processes 12:285-309.

DYER, B. 2000. Systematic review and biogeography of the freshwater fishes of Chile. Estudios Oceanológicos (Chile), 19:77-98.

Eschmeyer, W.N., Herald, E.S. \& Hammann, H. 1983. A field guide to Pacific coast fishes of North America. Houghton Mifflin Company, Boston, U.S.A. 336 pp.

Fernandez, H. \& Dominguez, E. 2002. Guía para la determinación de artrópodos bentónicos Sudaméricanos. Edit. Universitaria de Tucumán. Argentina. $282 \mathrm{pp}$.

Figueroa, R. \& Valdovinos, C. 1997. Productividad de pastizales salinos del estuario Lenga (Chile) a escala de paisaje ecológico: análisis de imágenes Landsat TM y experimentos in situ. Bol Soc. Biol. Concepción, Chile. 68:7-11.

Figueroa, R., Valdovinos, C., Araya, E. \& Parra, O. 2003. Macroinvertebrados bentónicos como indicadores de calidad del agua de ríos del sur de Chile. Revista Chilena de Historia Natural 76:275-285.

Figueroa, R., Ruiz, V.H., Araya, E., Niell, X. \& Palma, A. 2006. Invertebrates colonization patterns in a Mediterranean Chilean stream. Hydrobiología 571:409-417.

Figueroa, R., Palma, A., Ruiz, V.H. \& Niell, X. 2007 Análisis comparativo de índices bióticos utilizados en la evaluación de la calidad de las aguas en un río mediterráneo de Chile: río Chillán, VIII Región. Revista Chilena de Historia Natural 80 (2):225242.

Finlayson, C.M. 1999. Coastal wetlands and climate change: the role of governance and science. Aquatic Conserv. Mar. Freshw. Ecosyst. 56:621-626.

Fisher, T.S., HAYWARD, D.G., STEPHENS, R.D. \& STENTROM, M.K. 1999. Dioxins and furans in urban runoff. Journal of Environmental Engineering 125:185-191.

GALlEGO, J., FERNÁNDEZ, B., GARCÍA-MoRA, M.R. \& GARCÍANovo, F. 1999. Small wetlands lost: a biological conservation hazard in Mediterranean landscapes. Environmental Conservation 26:190-199.

Gayana. 2006. Biodiversidad dulceacuicola de Chile. Vol $70(1): 1-162$.

Geib. 2006. Las 20 especies exóticas invasoras más dañinas presentes en España. GEIB, Serie Técnica N.2.:116 pp.

GonzÁlez A. \& Victoriano, P. 2005. Aves de los humedales costeros de la zona de Concepción y alrededores. En: Historia, biodiversidad y ecología de los bosques costeros de Chile (Eds. Smith-Ramírez C., J. Armesto \& C. Valdovinos) pp. 485-497. Universitaria Bosque Nativo, Santiago, Chile.

GonzáLEZ, E.R. 2003. The freshwater amphipods Hyalella Smith, 1874 in Chile (Crustacea: Amphipoda). Revista Chilena de Historia Natural, 76:623-637.
Habit, E. 1998. Peces. En: Estudio de línea de base para la evaluación de impacto ambiental del complejo forestal industrial Itata. (Eds. Parra O. \& E. Habit) pp. 79-86. Ediciones Centro EULA-Chile, Universidad de Concepción.

Holland, C.C., Honea, J., Gwin, S.E. \& Kentula, M.E. 1995. Wetland degradation and loss in the rapidly urbanizing area of Portland, Oregon. Wetlands 15, 336-345.

ILlies J. 1963. Revision der Sudamericanischen Gripopterygidae (Plecoptera). Mitt. Schweiz. ent. Ges., Lausanne. 36(3):135-248.

Jáimez-Cuéllar, P., Vivas, S., Bonada, N., Robles, S. Mellado, A., Álvarez, M., Avilés, J., Casas, J., Ortega, M., Pardo, I., Prat, N., Rieradevall, M., Sáinz-Cantero, C.E., Sánchez-Ortega, A., Suárez, M.L., Toro, M., Vidal-Abarca, M.R., Zamora-Muñoz, C. \& Alba-Tercedor, J. 2004. Protocolo Guadalmed (PRECE). Limnética 21 (2002): 87-204.

LEE, J.H. \& BANG, K.W. 2000. Characterization of urban stormwater runoff. Water Research 34:1773-1780.

Leyse K.E., Lawler, S.P. \& Strange, T. 2003. Effects of an alien fish, Gambusia affinis, on an endemic California fairy shrimp, Linderiella occidentalis: implications for conservation of diversity in fishless waters. Biological Conservation, 10:35-46.

LunA, D. (ED.) 2005. Los humedales no pueden esperar. Manual para el uso racional del sistema de humedales costeros de Coquimbo. Corporación ambientes acuáticos de Chile (CAACH). 79 pp.

Mardones M. 1999. Contribución al conocimiento geomorfológico de las cuencas hidrográficas de los lagos Lanalhue y Lleu-Lleu. Revista Geográfica de Chile, Terra Australis, 44:87-106.

Mardones, M. \& Reuther, C. 1999. Geomorphological aspects of the drainage pattern around Lake Lanalhue and Lake Lleulleu in the active convergent margin setting of South-Central Chile. Mitt. Geol.-Paläont. Inst. 83:75-88.

Milton D.A. \& Arthington, A.H. 1983. Reproductive biology of Gambusia affinis holbrooki (Baird y Girard), Xhiphophorus helleri (Günther) and X. maculatus (Heckel) (Pisces; Poeciliidae) in Queensland, Australia. Journal of Fish Biology, 23:23-41.

Mrtsch, W. (ED.) 1994. Global Wetlands old world and new. Amsterdam, Elsevier, 967 pp.

Moreno J.M. (DIR.). 2005. Evaluación preliminar de los impactos en España por efecto del cambio climático. Ministerio de Medio Ambiente. Madrid. $549 \mathrm{pp}$.

Paracuellos, M. 2005. Los humedales como islas de agua en un mar de tierra: La biogeografía y ecología insulares, una vez al servicio de la conservación. En: Contrastes naturales en la región bioclimática del Mediterráneo. (Eds. Ballesteros G.A. \& R. Pérez), pp. 175-189. Museo de la Ciencia y el Agua (Ayuntamento de Murcia). España.

Parra, O., Valdovinos, C., Urrutia, R., Cisternas, M., Habit, E. \& Mardones, M. 2003. Caracterización 
y tendencias tróficas de cinco lagos costeros de Chile Central. Limnetica, 22: 51-83.

Pellet, P.F., Ugarte, E., Osorio, E. M. \& Herrera, F. 2005. Conservación de la biodiversidad en Chile, ¿legalmente suficiente?: La necesidad de cartografiar la ley antes de decidir. Revista Chilena de Historia Natural 78(1):125-141.

Ramírez, C. \& San Martín, C. 2006. Diversidad de macrófitos chilenos. Cap. II. Pp 21-69, en: Vila, I; A Veloso; R Schlatter \& C Ramírez (eds.). Macrófitas y vertebrados de los sistemas límnicos de Chile. Editorial Universitaria, Santiago, Chile.

RIEDE, K. 2004. Global register of migratory species - from global to regional scales. Final Report of the R\&DProjekt 808.05.081. Federal Agency for Nature Conservation, Bonn, Germany. 329 pp.

Riveros G, Sere, Y. \& Drouilly, P. (1981) Estructura y diversidad de la comunidad de aves acuáticas de la laguna El Peral, Chile central. Anales del Museo Nacional de Historia Natural 14:189-196.

RoJAS, M.E., TABILO-VALDIVIESO, E. 2004. Ficha informativa de los humedales Ramsar (FIR). Santuario de la Naturaleza. Laguna Conchalí. 15 pp.

Ruiz, V.H. \& Marchant, M. 1989. Sobre Cichlasoma facetum (Jenyns, 1842) (Perciformes, Cichlidae) en las Lagunas Grande y Chica de San Pedro (VIII Región, Chile) y observaciones de laboratorio. Bol. Soc. Biol. Concepción. 60:227-229.

Ruiz, V. H. \& Marchant, M. 2004. Ictiofauna de aguas continentales chilenas. Dirección de Docencia. Universidad de Concepción. 356 págs.

Salibian, A. 1977. Aclimatación de Gambusia affinis holbrooki (Girard, 1859) de Chile en soluciones de alta salinidad (Pisces, Poeciliidae). Not. Mens. Mus. Nac. Hist. Nat., XXII (253-254):4-7.

Semlitsch, R.D. \& Bodie, J.R. 1998. Are small, isolated wetlands expendable? Conservation Biology 12:1129-1133.

SMITH, C.L. 1997. National Audubon Society field guide to tropical marine fishes of the Caribbean, the Gulf of Mexico, Florida, the Bahamas, and Bermuda. Alfred A. Knopf, Inc., New York. 720 pp.

Squeo, F.A., Aravena, R., Aguirre, E., Pollastri, A., Jorquera, C.B. \& Ehleringer, J.R. 2006. Groundwater dynamics in a coastal aquifer in northcentral Chile: Implications for groundwater recharge in an arid ecosystem. Journal Aridest Environmental 67:240-254.

Stuardo. J., Valdovinos, C., Figueroa, R. \& Ochipinti, A. 1993. Los Ambientes Costeros del Golfo de Arauco y Áreas Adyacentes. Monografías Científicas $\mathrm{N}^{\circ}$ 9. Centro EULA/Chile, Universidad de Concepción.

Thomson, J.M. 1990. MUGILIDAE. In: Check-list of the fishes of the eastern tropical Atlantic (CLOFETA), Vol. 2. (Eds. Quero J.C., J.C. Hureau, C. Karrer,
A. Post \& L. Saldanha). pp. 855-859. JNICT, Lisbon; SEI, Paris and UNESCO, Paris.

UICN 2007. Lista Roja de Especies Amenazadas.

Valdovinos, C., Stuardo, J. \& Figueroa, R. 1993. Caracterización Ambiental del Estuario de Lenga (VIII Región, Chile). En: Planificación y gestión de la zona costera. Serie Planificación Territorial. Centro EULA-Chile. Universidad de Concepción.

VArios Autores. 2003. Los Humedales de la Región de Murcia. Humedales y ramblas de la Región de Murcia. Murcia. Consejería de Agricultura, Agua y Medio Ambiente. Comunidad Autónoma de la Región de Murcia.137 pp.

Victoriano, P.F., GonZalez, A.L. \& Schlatter, R.. 2006. Estado del conocimiento de las aves de agues continentals de Chile. Gayana, 70:140-160.

Vidal-Abarca, M.R., Suárez, M.L. \& Gómez, R. 2000. Los humedales: Ecosistemas para conservar. En: Biodiversidad. Contribución a su conocimiento y conservación en la Región de Murcia. pp. 149-162. (Eds. Calvo, J.F.; M.A. Esteve; F. López Bermúdez). Servicio de Publicaciones de la Universidad de Murcia. España.

Vila I., Fuentes, L. \& Contreras, M.. 1999. Peces límnicos de Chile. Boletín del Museo de Historia Natural, Chile. 48: 61- 75.

Vila, I., Veloso, A., Schlatter, R. \& Ramírez, C. (Eds.). 2006. Macrofitas y vertebrados de los sistemas límnicos de Chile. Editorial Universitaria. Santiago de Chile.

Villagrán-Mella, R., Aguayo, M., Parra, L. \& González, A. 2006. Relación entre características del hábitat y estructura del ensamble de insectos en humedales palustres urbanos del centro-sur de Chile. Revista Chilena de Historia Natural, 79:195-211.

WaHL M.H., Mckellarr, H.N. \& Williams, T.M. 1997. Patterns of nutrient loading in forested and urbanized coastal streams. Journal of Experimental Marine Biology and Ecology 213:111-131.

Welcomme, R.L. 1988. International introductions of inland aquatic species. FAO Fish. Tech. Pap. 294. 318 pp.

Wernick, B.G., CoOK, K.E. \& SchreIER, H. 1998. Land use and streamwater nitrate-N dynamics in an urbanrural fringe watershed. Journal of the American Water Resources Association 34;639-650.

Wfid Cis. Guidance Doc No 12. 2003. Horizontal Guidance on the role of wetlands in the Water Framework Directive. Published by the Directorate General Environment of the European Commission, Brussels, ISBN nº. 92-894-6967-6. ISSN 1725-1087.

Zamora-Muñoz C. \& Alba-Tercedor, J. 1996. Bioassessment of organic polluted Spanish rivers, using a biotic index a multivariate methods. Journal of the North American Benthological Society $15: 332-352$. 